\title{
Subgingival microbial profile of women with breast cancer: a cross-sectional study
}

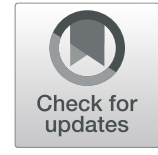

\author{
Vivian Rodrigues Bernhard ${ }^{1}$, Marcelo Faveri ${ }^{2}$, Marciel Silva Santos ${ }^{1 \wedge}$, Maria da Conceição Machado Gomes ${ }^{1}$, \\ Roberta Grasseli Batitucci ${ }^{1}$, Caio Junji Tanaka ${ }^{2 *}$, Magda Feres² and Alfredo Feitosa'
}

\begin{abstract}
Background: Some prospective studies have observed associations between periodontal disease and breast cancer. Therefore, the aim of the present study was to investigate the composition of the subgingival biofilm of women diagnosed with breast cancer, who also presented with chronic periodontitis.

Methods: All subjects underwent clinical and microbiological assessment. Subgingival biofilm samples were taken from at least three sites of 44 women who had breast cancer. The mean levels and proportions of 40 bacterial species were determined by checkerboard DNA-DNA hybridization. Spearman correlation was used to assess possible associations between the mean levels of bacterial species and clinical conditions.

Results: The five species found at the highest levels were Prevotella nigrescens, Actinomyces gerencseriae, Neisseria mucosa, Porphyromonas gingivalis and Tannerella forsythia. The species detected in the lowest counts were Propionibacterium acnes, Streptococcus constellatus, Streptococcus intermedius, Eubacterium saburreum and Streptococcus anginosus. No significant association between levels and proportion of bacterial species and clinical parameters were found.
\end{abstract}

Conclusion: In conclusion, the results of the present study found no direct association between the subgingival microbiota and breast cancer and an indirect pathway should be addressed in further studies.

Trial registration: Retrospectively registered.

Keywords: Breast cancer, Periodontitis, Subgingival microbiota, Risk factor, Cancer

\section{Clinical relevance}

Scientific rationale for study: Periodontitis is an extremely prevalent disease and has been associated with a risk factor for breast cancer. However, up to now, no studies have aimed to analyze the subgingival microbiota of women with breast cancer who also had periodontitis. Principal findings: The subgingival biofilm was colonized predominantly by Gram-negative species. Two species from the red complex P.gingivalis and T.forsythia were the species with the highest mean counts. Practical implications. Although no association between subgingival microbial profile and breast cancer was found, subgingival

\footnotetext{
* Correspondence: caiotanaka@outlook.jp

${ }^{2}$ Department of Periodontology, Dental Research Division, Guarulhos

University, Guarulhos, São Paulo, Brazil

Full list of author information is available at the end of the article
}

microbiota can increase the expression of virulence and this relation should be investigated.

\section{Background}

Chronic periodontitis (ChP) is characterized by polymicrobial infection and inflammation of the periodontium that result in loss of connective tissue and alveolar bone surrounding the teeth $[1,2]$. It has been associated with increased risk of systemic illnesses, including diabetes mellitus [3-5], cardiovascular disease [6, 7] respiratory disease $[8,9]$ and rheumatoid arthritis [10-12]. Indeed, ChP promotes systemic inflammation via translocation of oral bacteria, bacterial toxins, and inflammatory mediators through frequent transient bacteremia that would heighten the systemic burden and could promote cellular differentiation $[4,13]$. In addition, ChP has also been associated with cancers of the head and neck [14, 15], pancreas [16], lung [17], and more recently breast cancer $[18,19]$. 
Breast cancer is an important public health disease. New estimates indicate that it is the second most common cancer around the world and the most frequent cancer among women [20]. Some prospective studies have observed associations between periodontal disease and breast cancer [18, 19, 21]. Freudenheim et al. [18] observed a higher risk of breast cancer among study participants who self-reported having periodontal disease, using data from 73.737 postmenopausal women followed up for 6.7 years. Sfreddo et al. [19] in a case control study, reported that women diagnosed with periodontitis had two to three times higher odds of breast cancer than women without periodontitis. Some hypotheses have been suggested to explain a possible association between cancer and periodontitis. The most frequently advocated biological plausibility is that persistent periodontal infection and inflammation induce a chronic systemic inflammatory state, which could act in a protumour fashion at distant sites [14]. However, no studies to date have analyzed the microbial profile of the subgingival biofilm of women with breast cancer and periodontitis. Therefore, the aim of this study was to explore the microbial composition of women diagnosed with breast cancer, who also had periodontitis.

\section{Materials and methods}

\section{Subject population}

This cross-sectional study was performed between November 2014 and April 2015 at the Department of Gynecology at the University Hospital Cassiano Antônio de Moraes (HUCAM) Vitoria, Brazil. The study was conducted according to the declaration of Helsinki and was approved by the Committee on Ethics in Research with Human Beings of the Health Sciences Center (UFES) (IRB:862.952). Accordingly, the study protocol was explained to each subject, and a signed informed consent was obtained. Forty-four women diagnosed with breast cancer (ICD-10 C50) at the Mastology Clinic were selected. No restrictions regarding cancer staging and cancer treatment were used.

\section{Inclusion criteria}

The inclusion criteria were as follows: women having breast cancer, aged between 35 to 75 years, $>10$ teeth and at least one teeth with probing depth (PD) and clinical attachment level $(\mathrm{CAL}) \geq 4 \mathrm{~mm}$. Breast cancer had been diagnosed by board-certified gynaecologists specialized in mastology using standard diagnostic procedures defined by Brazilian National Institute of Cancer (INCA) which included mammograms, ultrasounds, fine needle aspiration, core needle biopsy and excisional biopsy, as needed. Biopsy specimens were evaluated by medical pathologists.

\section{Exclusion criteria}

Women who needed antibiotic prophylaxis prior to oral examinations, or who were wearing fixed orthodontic appliances, using medications associated with gingival overgrowth (nifedipine, cyclosporine and phenytoin), diagnosed with psychomotor disorders, had taken antibiotics drugs within 6 months before the clinical examination were not included.

\section{Data collection and clinical monitoring}

A trained interviewer (VRB) used a structured questionnaire to collect data on demographic characteristics, socioeconomic status, lifestyle exposure and medical history. In addition, data including cancer diagnosis, treatment type and duration, and medications were collected from each participant's medical record using a standardized form. Clinical monitoring was performed by one calibrated examiner (VRB). Visible plaque index (VPI presence or absence), bleeding on probing (BOP; presence or absence), PD ( $\mathrm{mm}$ ) and CAL ( $\mathrm{mm})$ were measured at 6 sites per tooth (mesiobuccal, buccal, distobuccal, distolingual, lingual and mesiolingual) in all teeth, excluding third molars. The PD and CAL measurements were recorded to the nearest millimeter using a North Carolina periodontal probe (Hu-Friedy, Chicago, IL, USA).

\section{Microbiological monitoring}

Subgingival plaque samples were collected from 3 to 4 non-contiguous interproximal sites per subject with $\mathrm{PD} \geq 4 \mathrm{~mm}$. After the clinical parameters had been recorded, the supragingival plaque was removed and the subgingival samples were taken with individual sterile mini-Gracey curettes (\#11-12) and immediately placed in separate Eppendorf tubes containing $0.15 \mathrm{ml}$ of TE (10 mM Tris- $\mathrm{HCl}, 1 \mathrm{mM}$ EDTA, pH 7.6). One hundred microliters of $0.5 \mathrm{M} \mathrm{NaOH}$ was added to each tube and the samples were dispersed using a vortex mixer. Counts of 40 bacterial species were determined in each sample, using the checkerboard DNA-DNA hybridization

Table 1 Demographic characteristics and mean $( \pm S D)$ fullmouth clinical parameters of the subjects in experimental group

\begin{tabular}{ll}
\hline Variables & Chronic periodontitis \\
\hline Subjects $(\mathrm{n})$ & 44 \\
Age (years) & $51.0 \pm 7.0$ \\
Probing depth (mm) & $2.23 \pm 0.45$ \\
Clinical attachment level (mm) & $2.51 \pm 0.69$ \\
Mean number of sites with PS $\geq 4 \mathrm{~mm}$ & $13.0 \pm 11.1$ \\
\% sites with & \\
Plaque & $40 \pm 45$ \\
Bleeding on probing & $22 \pm 22$ \\
\hline
\end{tabular}

SD Standard deviation 
Table 2 Mean $( \pm S D)$ clinical parameters of the sites analyzed microbiologically

\begin{tabular}{ll}
\hline Variables & Chronic periodontitis \\
\hline Number of samples & 144 \\
Probing depth $(\mathrm{mm})$ & $4.7 \pm 0.4$ \\
Clinical attachment level $(\mathrm{mm})$ & $2.0 \pm 2.6$ \\
$\%$ sites with & \\
$\quad$ Plaque & $80 \pm 12$ \\
$\quad$ Bleeding on probing & $92 \pm 10$
\end{tabular}

technique $[22,23]$ at the Laboratory of Microbiology of Guarulhos University.

Briefly, samples were boiled for $10 \mathrm{~min}$ and $800 \mu \mathrm{l}$ of $5 \mathrm{~mol} / \mathrm{L}$ ammonium acetate was added to promote bacterial lyses and consequent suspension of DNA in solution. A nylon membrane $(15 \times 15 \mathrm{~cm})$, with positive charge (Hybond $\mathrm{N}+{ }^{\mathrm{m}}$-Amersham, GE Healthcare Limited, Buckinghamshire, England, UK), was placed in a MiniSlot $30^{\circ}$ (Immunetics, Cambridge, MA, USA) and $1000 \mu \mathrm{l}$ of each suspension was placed into the extended slots of the MiniSlot $30^{\circ}$ and fixed to the membrane by baking it at $120^{\circ} \mathrm{C}$ for $20 \mathrm{~min}$. In each membrane 28 samples are placed and the last two channels of Minislot $30^{\circ}$ are reserved for the placement of controls, containing a mixture of species of microorganisms that have been investigated by DNA probes, in two concentrations, $10^{5}$ and $10^{6}$ bacterial cells. A Miniblotter $45^{\circ}$ (Immunetics, Cambridge, MA, EUA) device was used to hybridize the digoxigeninlabeled whole-genomic DNA probes perpendicular to the lanes of the clinical samples. Prior to the examination of the samples, the probes are tested to calibrate the controls.

Bound probes were detected through the use of phosphatase-conjugated antibodies to digoxigenin and chemiluminescence (CDP-Star Detection Reagent ${ }^{\mathrm{Tm}}$, Amersham, GE Healthcare Limited, Buckinghamshire, England, UK). The membranes were placed under a radiographic film (AGFA ${ }^{\circ}$-IBF, Duque de Caxias, RJ, Brazil) by approximately sixty minutes. The films were revealed shortly thereafter. Each probe produces a certain type of signal, which was visually compared to the

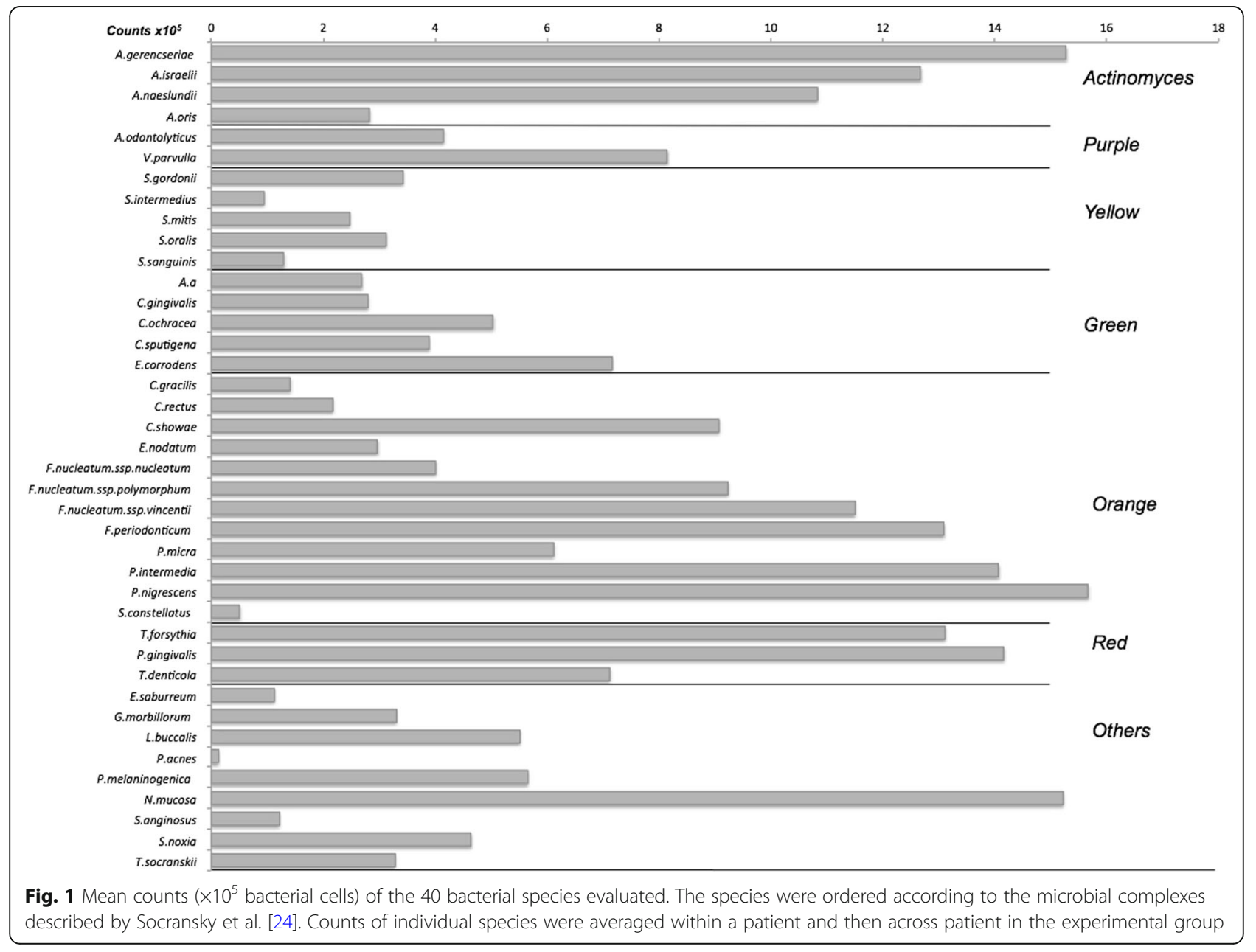


signals produced by the probes in the two controls containing $10^{5}$ and $10^{6}$ bacteria. The signals were scored related to the count levels observed: (0) not detected; (1) $<10^{5}$ cells; (2) nearly $10^{5}$ cells; (3) between $10^{5}$ and $10^{6}$ cells; (4) nearly $10^{6}$ cells; (5) $>10^{6}$ cells. Signals were also coded for presence (0) or absence (1) of each tested bacterial species. The sensitivity of this assay permitted the detection of $10^{4}$ cells of a given bacterial species by adjusting the concentration of each DNA probe.

\section{Statistical analysis}

The mean age and mean percentage of sites with VPI and BOP as well as mean full-mouth PD and CAL and mean sample sites PD and CAL were computed for each subject and then averaged across subjects.

Microbiological data were express in proportions and levels of each species in each sample at the baseline visit. Mean counts $\times 10^{5}$ of each species were computed for each sample and then averaged across subjects. Spearman correlation was used to assess possible associations between the mean levels of bacterial species and clinical conditions. The level of significance was set at $5 \%$.

\section{Results}

The demographic characteristics and clinical parameters of the studied population and the sampled sites are presented in Tables 1 and 2, respectively. A total of fortyfour women diagnosed with breast cancer participated in this investigation. This population presented a mean number of sites with $\mathrm{PD} \geq 4 \mathrm{~mm}$ of $13.0 \pm 11.1$ (Table 1) and the mean PD and $\overline{C A L}$ of the sites analyzed was $4.7 \pm 2.6 \mathrm{~mm}$ and $2.0 \pm 2.6 \mathrm{~mm}$ (Table 2), respectively.

The mean counts $\left(\times 10^{5} \pm\right.$ SEM $)$ and mean percentage of DNA probe counts (proportions) of the 40 species evaluated are presented in Figs. 1 and 2, respectively. The five species found at the highest levels $\left(10^{5} \pm\right.$ SEM) were Prevotella nigrescens $(15.6 \pm 2.4)$, Actinomyces gerencseriae (15.2 \pm 2.4$)$, Neisseria mucosa (15.2 \pm 2.3$)$, Porphyromonas gingivalis $(14.1 \pm 2.7)$ and Tannerella forsythia $(13.1 \pm 2.5)$. The species detected in the lowest counts were Propionibacterium acnes $(0.1 \pm 0.02)$, Streptococcus constellatus

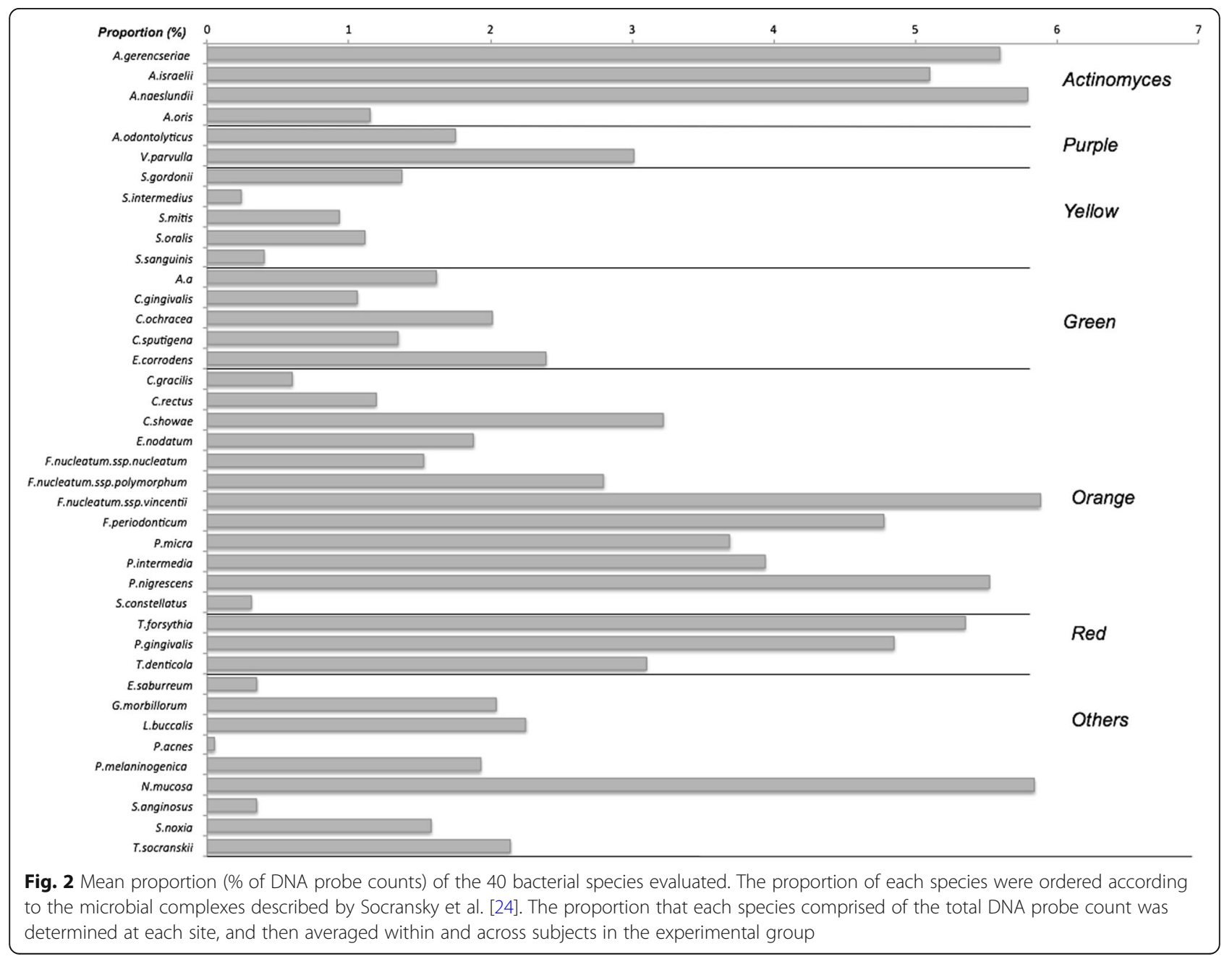


(0.5 \pm 0.1$)$, Streptococcus intermedius $(0.9 \pm 0.1)$, Eubacterium saburreum $(1.1 \pm 0.2)$ and Streptococcus anginosus (1.2 \pm 0.2$)$ (Fig. 1).

Seven species was found over $5 \%$ of the total of microbiota analyzed been Fusobacterium nucelatum ssp nucleatum, N mucosa, Actinomyces naeslundii, A. gerencseriae, P. nigrescens, T. forsythia and P.gingivalis (Fig. 2). The species found in the lowest proportion, below to $1 \%$ of the total of microbiota were C. gracilis, Streptococcus sanguinis, E. saburreum, S. anginosus, S. constelattus, S. intermedia and $P$. acnes.

The mean proportion of the microbial complexes presented in the subgingival biofilm of women with breast cancer are described in Fig. 3. The orange and red complex were found in almost $50 \%$ of the microbial load, 35.3 and $13.3 \%$, respectively. Actinomyces species were found in $17.6 \%$ and others species not found in the microbial complex was found in $16.5 \%$. No significant association between levels and proportion of bacterial species and clinical parameters were found.

\section{Discussion}

Nowadays, a great deal of research effort has been dedicated to understanding the impact of the oral microbial burden on systemic health. It is well recognized that periodontal infection increases the level of inflammatory markers in the blood, and several studies [14-17] have linked this persistent inflammation to the development of different types of cancer, including breast cancer $[18,19,25]$. Therefore, defining the microbial profile of women with breast cancer and

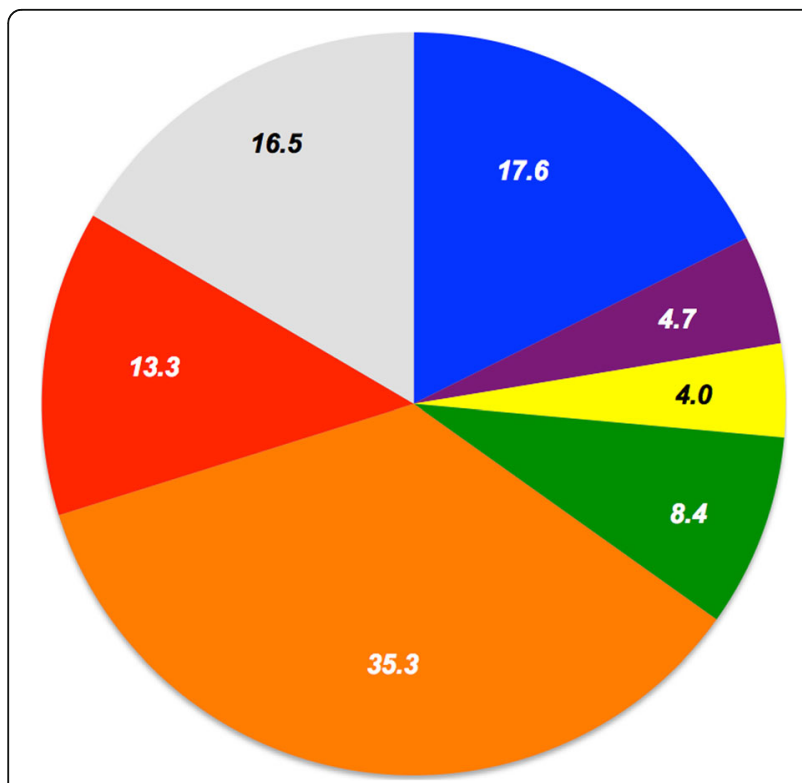

Fig. 3 Pie charts of the mean proportion of each microbial complex in the experimental group. The colors represent different microbial complexes [24] periodontitis is important contributory data to our understanding of the relationship between periodontitis and this systemic condition. To our knowledge, this is the first report in which the composition of the subgingival microbiota of woman with breast cancer has been extensively evaluated. The levels and proportions of 40 bacterial species in 144 subgingival plaque samples from 44 subjects were analyzed.

The subgingival biofilm of our experimental group was colonized predominantly by Gram-negative species. Two species from the red complex $P$. gingivalis and $T$. forsythia were the species with the highest mean counts. In addition, higher levels of some putative periodontal pathogens from the orange complex were also found in the subgingival biofilm of women with breast cancer, especially species of Fusobacterium sp. and Prevotella sp. It is important to note that the microbial profile of our study population was in agreement with previous studies that found higher levels of these bacterial species in the subgingival biofilm of subjects with periodontitis [26-28] and no differences were observed between our data and the data provided by the literature. However, it is important to highlight that our study population presented a clinical profile compatible with mild periodontitis, and we also found a complex microbiota in their subgingival biofilm. Therefore, an indirect pathway from periodontitis and breast cancer could be hypothesized and the chronic inflammation resulting from the periodontal infection can be one of the risk factor for the development of this type of cancer. The relation with chronic inflammation and cancer was reported by Coussens and Werb [29]. Therefore, the presence of lipopolysaccharides (LPS) that are component of Gram-negative bacteria, which can cause chronic inflammation may be a potential candidate to connect periodontitis and breast cancer.

In according to Mager et al. [30], estimates have indicated that over $15 \%$ of malignancies worldwide could be related to infections. Some studies have reported association between oral bacteria species and different types of cancer [31, 32]. Gao et al. [32] reported an association of $P$. gingivalis and $T$. denticola with tumorigenesis of esophageal cancer. Porphyromonas gingivalis and Fusobacterium nucleatum has shown strong oral carcinogenic potential in vitro and in animal studies [14, 31, 33]. Mager et al. [29] reported that high salivary counts of Capnocytophaga gingivalis, Prevotella melaninogenica and Streptococcus mitis may be diagnostic indicators of oral squamous cell carcinoma. Therefore, during 'dysbiosis' these oral bacterial can increase the expression of virulence factors leading to an inflammation status of the host $[14,33]$ and produce a chronic inflammation through different pathways including the activation of the caspase-1 inflammasome [34]. 
Inflammasomes are multiprotein complexes localized within the cytoplasm of the cell [35]. According to Karki et al. [34] excessive inflammation driven by the inflammasome or the interleukin-1 (IL-1) signaling pathways can promote breast cancer, gastric carcinoma, fibrosarcoma, and lung metastasis. Kolb et al. [36] reported that caspase recruitment domain-containing protein 4 (NLRC4) inflammasome mediates expression of adipocyte-mediated vascular endothelial growth factor A (VEGFA), and accelerates the progression of breast cancer. Recently, it was found that P.gingivalis and Fusobacterium nucleatum [35], may develop different mechanisms to inhibit inflammasome activation and function, and therefore this systemic inflammation could indirectly contribute to systemic cancer such as breast cancer [29].

Despite the possible association between breast cancer and periodontitis $[18,19,25]$, the components and products involved in the mechanisms of induction of carcinogenesis are unknown and further studies with a large sample size and a control group should be conducted with the purpose of elucidating this issue. Indeed, public data on this topic will be very important for public health assistance.

\section{Conclusion}

In conclusion, the results of the present study found no direct association between the subgingival microbiota and breast cancer and an indirect pathway should be addressed in further studies.

\section{Abbreviations \\ BOP: Bleeding on probing; CAL: Clinical attachment level; ChP: Chronic periodontitis; DNA: Deoxyribonucleic acid; IL-1: Interleukin-1; MM: Milimeter; NLRC4: Domain-containing protein 4; PD: Probing depth; SD: Standard deviation; VEGFA: Vascular endothelial growth factor A; VPI: Visible plaque index}

\section{Acknowledgments}

We acknowledge the Espírito Santo Research Foundation (FAPES, Brazil) for the Master's Degree Scholarship of the first author (Process number: 66867240)

\section{Authors' contributions \\ VRB, MF, MFF, AF (concept, data acquisition, data analysis, writing manuscript, final review); MSS, MCMG, RGB, CJT (data acquisition, data analysis, writing manuscript); All authors read and approved the final manuscript.}

\section{Funding}

This study was funding by Research Grants 2013/10139-6 from São Paulo Research Foundation (FAPESP, Brazil).

\section{Availability of data and materials}

The datasets generated and/or analyzed during this study are available from the corresponding author on reasonable request.

\section{Ethics approval and consent to participate}

The Ethical Committee of Health Sciences Center/ UFES approved this study procedure on November 25, 2014 (Approval Number: 862.952). All patients recruited gave written consent to participate in the study.

\section{Consent for publication}

All authors agreed to publish.

\section{Competing interests}

The authors declare no potential conflicts of interest with respect to the authorship and/or publication of this article.

\section{Author details}

${ }^{1}$ Postgraduate Program in Dental Clinic/PPGCO and Department of Dental Clinic, Espirito Santo Federal University, Vitória, Espirito Santo, Brazil.

${ }^{2}$ Department of Periodontology, Dental Research Division, Guarulhos University, Guarulhos, São Paulo, Brazil.

Received: 26 March 2019 Accepted: 24 September 2019

Published online: 04 November 2019

\section{References}

1. Socransky SS, Haffajee AD. Periodontal microbial ecology. Periodontol 2000. 2005; 38(1):135-187.

2. Feres $M$, Figueiredo $L C$, Soares $G M$, Faveri M. Systemic antibiotics in the treatment of periodontitis. Periodontol 2000. 2015; 67(1):131-138.

3. Chee B, Park B, Bartold PM. Periodontitis and type II diabetes: a two-way relationship. Int J Evid Based Healthc. 2013;11(4):317-29.

4. Linden GJ, Herzberg MC. Periodontitis and systemic diseases: a record of discussions of working group 4 of the joint EFP/AAP workshop on periodontitis and systemic diseases. J Periodontol. 2013:84(4 Suppl):S20-3.

5. Artese HP, Foz AM, Rabelo M de S, Gomes GH, Orlandi M, Suvan J, D'Aiuto F, Romito GA. Periodontal therapy and systemic inflammation in type 2 diabetes mellitus: a meta-analysis. PLoS One. 2015; 10(5):e0128344.

6. Kinane DF, Lowe GD. How periodontal disease may contribute to cardiovascular disease. Periodontol 2000. 2000: 23(2):121-126.

7. Dietrich T, Webb I, Stenhouse L, Pattni A, Ready D, Wanyonyi KL, White S, Gallagher JE. Evidence summary: the relationship between oral and cardiovascular disease. Br Dent J. 2017;222(5):381-5.

8. Armitage GC. Periodontal infections and cardiovascular disease--how strong is the association? Oral Dis. 2000;6(6):335-50.

9. Han P, Sun D, Yang J. Interaction between periodontitis and liver diseases. Biomed Rep. 2016;5(3):267-76.

10. Balci Yuce H, Gokturk O, Aydemir Turkal H, Inanir A, Benli I, Demir O. Assessment of local and systemic 25-hydroxy-vitamin D, RANKL, OPG, and TNF levels in patients with rheumatoid arthritis and periodontitis. J Oral Sci. 2017:59(3):397-404.

11. Lin CH, Chen DY, Chao WC, Liao TL, Chen YM, Chen HH. Association between periodontitis and the risk of palindromic rheumatism: a nationwide, population-based, case-control study. PLoS One. 2017;12(8): e0182284.

12. Domínguez-Pérez RA, Loyola-Rodriguez JP, Abud-Mendoza C, Alpuche-Solis AG, Ayala-Herrera JL, Martínez-Martínez RE. Association of cytokines polymorphisms with chronic periodontitis and rheumatoid arthritis in a Mexican population. Acta Odontol Scand. 2017;75(4):243-8.

13. Cullinan MP, Seymour GJ. Periodontal disease and systemic illness: will the evidence ever be enough? Periodontol 2000. 2013; 62(1):271-286.

14. Gholizadeh P, Eslami H, Yousefi M, Asgharzadeh M, Aghazadeh M, Kafil HS Role of oral microbiome on oral cancers, a review. Biomed Pharmacother. 2016:84:552-8.

15. Moraes RC, Dias FL, Figueredo CM, Fischer RG. Association between chronic periodontitis and Oral/Oropharyngeal Cancer. Braz Dent J. 2016;27(3):261-6.

16. Chang JS, Tsai CR, Chen LT, Shan YS. Investigating the association between periodontal disease and risk of pancreatic Cancer. Pancreas. 2016:45(1):134-41.

17. Mai X, LaMonte MJ, Hovey KM, Freudenheim JL, Andrews CA, Genco RJ, Wactawski-Wende J. Periodontal disease severity and cancer risk in postmenopausal women: the Buffalo OsteoPerio study. Cancer Causes Control. 2016;27(2):217-28.

18. Freudenheim JL, Millen AE, Wactawski-Wende J. Periodontal disease and breast Cancer-response. Cancer Epidemiol Biomark Prev. 2016;25(5):862.

19. Sfreddo CS, Maier J, De David SC, Susin C, Moreira CHC. Periodontitis and breast cancer: A case-control study. Community Dent Oral Epidemiol. 2017; Jun 27. (in press).

20. Cancer Research UK. Cancer Statistics for the UK. Disponivel em: <http://www. cancerresearchuk.org/health-professional/cancer-statistics\# heading -Zero>. Access on: august $20^{\text {th }} 2017$. 
21. Söder B, Yakob M, Meurman JH, Andersson LC, Klinge B, Söder PÖ. Periodontal disease may associate with breast cancer. Breast Cancer Res Treat. 2011;127(2):497-502.

22. Socransky SS1, Smith C, Martin L, Paster BJ, Dewhirst FE, Levin AE. "Checkerboard" DNA-DNA hybridization. Biotechniques. 1994; 17(4):788-92.

23. Mestnik MJ, Feres M, Fiqueiredo LC, Duarte PM, Lira EA, Faveri M. Short-term benefits of the adjunctive use of metronidazole plus amoxicillin in the microbial profile and in the clinical parameters of subjects with generalized aggressive periodontitis. J Clin Periodontol. 2010;37(4):353-65.

24. Socransky SS, Haffajee AD, Cugini MA, Smith C, Kent RL Jr. Microbial complexes in subgingival plaque. J Clin Periodontol. 1998;25(2):134-44.

25. Dizdar O, Hayran M, Guven DC, YIImaz TB, Taheri S, Akman AC, Bilgin E, Hüseyin B, Berker E. Increased cancer risk in patients with periodontitis. Curr Med Res Opin. 2017;11:1-6.

26. Haffajee AD, Bogren A, Hasturk H, Feres M, Lopez NJ, Socransky SS. Subgingival microbiota of chronic periodontitis subjects from different geographic locations. J Clin Periodontol. 2004;31(11):996-1002.

27. Gonçalves C, Soares GM, Faveri M, Pérez-Chaparro PJ, Lobão E, Figueiredo $L C$, Baccelli GT, Feres M. Association of three putative periodontal pathogens with chronic periodontitis in Brazilian subjects. J Appl Oral Sci. 2016;24(2):181-5.

28. Feres M, Louzoun Y, Haber S. Faveri M. Levin L. Support vector machinebased differentiation between aggressive and chronic periodontitis using microbial profiles. Int Dent J: Figueiredo LC; 2017. (in press)

29. Lisa M. Coussens and Zena Werb. Inflammation and cancer Nature 2002 Dec 19; 420(6917): 860-867.

30. Mager DL, Haffajee AD, Devlin PM, Norris CM, Posner MR, Goodson JM. The salivary microbiota as a diagnostic indicator of oral cancer: a descriptive, non-randomized study of cancer-free and oral squamous cell carcinoma subjects. J Transl Med. 2005;7:3-27.

31. Nagy K, Sonkodi I, Szöke I, Nagy E, Newman H. The microflora associated with human oral carcinomas. Oral Oncol. 1998;34:304-8.

32. Gao S, Li S, Ma Z, Liang S, Shan T, Zhang M, Zhu X, Zhang P, Liu G, Zhou F, Yuan X, Jia R, Potempa J, Scott DA, Lamont RJ, Wang H, Feng X. Presence of Porphyromonas gingivalis in esophagus and its association with the clinicopathological characteristics and survival in patients with esophageal cancer. Infect Agent Cancer. 2016:19:11-3.

33. Binder Gallimidi A, Fischman S, Revach B, Bulvik R, Maliutina A, Rubinstein AM, Nussbaum G, Elkin M. Periodontal pathogens Porphyromonas gingivalis and Fusobacterium nucleatum promote tumor progression in an oralspecific chemical carcinogenesis model. Oncotarget. 2015;6(26):22613-23.

34. Karki R, Man SM, Kanneganti TD. Inflammasomes and Cancer. Cancer Immunol Res. 2017;5(2):94-9.

35. Olsen I, Yilmaz Ö. Modulation of inflammasome activity by Porphyromonas gingivalis in periodontitis and associated systemic diseases. J Oral Microbiol. 2016; 4;8:30385

36. Kolb R, Phan L, Borcherding N, Liu Y, Yuan F, Janowski AM, et al. Obesity associated NLRC4 inflammasome activation drives breast cancer progression. Nat Commun. 2016;7:13007.

\section{Publisher's Note}

Springer Nature remains neutral with regard to jurisdictional claims in published maps and institutional affiliations.

Ready to submit your research? Choose BMC and benefit from:

- fast, convenient online submission

- thorough peer review by experienced researchers in your field

- rapid publication on acceptance

- support for research data, including large and complex data types

- gold Open Access which fosters wider collaboration and increased citations

- maximum visibility for your research: over $100 \mathrm{M}$ website views per year

At BMC, research is always in progress.

Learn more biomedcentral.com/submissions 